\title{
Lecture Notes in Artificial Intelligence
}

Subseries of Lecture Notes in Computer Science

Edited by J. G. Carbonell and J. Siekmann

Lecture Notes in Computer Science

Edited by G. Goos and J. Hartmanis

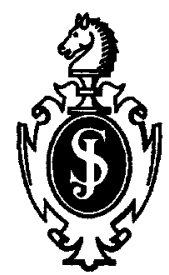




\section{Daniel Hernández}

\section{Qualitative Representation of Spatial Knowledge}

Springer-Verlag

Berlin Heidelberg New York

London Paris Tokyo

Hong Kong Barcelona

Budapest 


\section{Series Editors}

Jaime G. Carbonell

School of Computer Science, Carnegie Mellon University

Schenley Park, Pittsburgh, PA 15213-3890, USA

Jörg Siekmann

University of Saarland

German Research Center for Artificial Intelligence (DFKI)

Stuhlsatzenhausweg 3, D-66123 Saarbrücken, Germany

\section{Author}

Daniel Hernández

Fakultät für Informatik, Technische Universität München

Arcisstraße 21, D-80290 München, Germany

CR Subject Classification (1991): I.2.4, I.2.0, I.2.1, I.2.3, J.6

ISBN 3-540-58058-1 Springer-Verlag Berlin Heidelberg New York ISBN 0-387-58058-1 Springer-Verlag New York Berlin Heidelberg

\section{CIP data applied for}

This work is subject to copyright. All rights are reserved, whether the whole or part of the material is concerned, specifically the rights of translation, reprinting, re-use of illustrations, recitation, broadcasting, reproduction on microfilms or in any other way, and storage in data banks. Duplication of this publication or parts thereof is permitted only under the provisions of the German Copyright Law of September 9, 1965, in its current version, and permission for use must always be obtained from Springer-Verlag. Violations are liable for prosecution under the German Copyright Law.

(C) Springer-Verlag Berlin Heidelberg 1994

Printed in Germany

Typesetting: Camera ready by author

SPIN: $10131112 \quad 45 / 3140-543210$ - Printed on acid-free paper 


\section{Preface}

Cognitive spatial concepts are qualitative in nature, i.e., they are based not so much on exact quantities but on comparisons between perceived magnitudes. We develop a qualitative model for the representation of spatial knowledge (in particular, of positional information about 2-dimensional projections) that is based only on locative relations between the objects involved, does not need a global scale, and takes different kinds of reference frames into consideration. The resulting model is both cognitively plausible and computationally efficient.

The core of the book is the study of qualitative inference methods. We extend constraint reasoning mechanisms to take the rich structure of physical space into consideration, and describe methods to transform among reference frames and for the composition of relations. We also sketch extensions of the qualitative approach to represent positional information in 3-D scenes, as well as other spatial concepts such as size, shape, and distance.

Qualitative representations make only as many distinctions as necessary to identify objects, events, situations, etc. in a given context (recognition task) as opposed to those needed to fully reconstruct a situation (reconstruction task). Thus, they can be used in many application areas from everyday life in which spatial knowledge plays a role, particularly in those that are characterized by uncertain and incomplete knowledge, such as computer aided systems for architectural design, geographical information systems, but also robot control or natural language information systems to give directions.

This book is a revised version of a dissertation submitted to the Institut für Informatik (Department of Computer Science) of the Technische Universität München (Munich, Germany) in December of 1992. In the meantime, interest in qualitative models of space has multiplied as reflected by several recent workshops and conference sections on the subject (QUARDET 93, COSIT 93, IJCAI 93, KI-93). ${ }^{1}$ Taking all of these new developments fully into account is impossible within the time allotted for revision, and without a complete rewrite of several parts of the text. However, I have tried to compile the references to newer published work in the bibliography, and to point to them in the appropriate sections.

I am indebted to Wilfried Brauer and Christopher Habel for their guidance

\footnotetext{
${ }^{1}$ Proceedings edited by Piera Carreté and Singh (1993), Frank and Campari (1993), Anger, Guesgen, and van Benthem (1993), and Hernández (1993c) respectively.
} 
and support. Christian Freksa's insights inspired much of this work. The former and present members of the AI/Cognition Group provided the academic and computing environment that made this book possible. My colleagues Martin Eldracher, Margit Kinder, and Gerhard Weiß took much of the administrative burden from my shoulders during the final phase of this work. I had many fruitful discussions with Stephan Högg, Irmgard Schwarzer, and Kai Zimmermann. Daniel Kobler contributed through his own research work, through detailed proofreading of draft versions, and with clever TEX-macros to draw the icons of many tables. Viola Krings made an excellent job drawing some of the figures and tables. I want to thank Christopher Habel's group at the Universität Hamburg, particularly Simone Pribbenow, Ralf Röhrig, Rolf Sander, and Christoph Schlieder, and Josef Schneeberger (TH Darmstadt) for their critical interest in my work. Finally, I would like to express my appreciation for the hints provided by the anonymous reviewers, the help and patience of the editorial staff at Springer, and the many other people who contributed in various forms to the completion of this book.

February 1994

Daniel Hernández 


\section{Contents}

1 Introduction 1

1.1 The relevance of spatial knowledge . . . . . . . . . . . 1

1.2 The problem and why it should be solved . . . . . . . . 2

1.3 The kind of solution sought $\ldots \ldots \ldots \ldots \ldots \ldots$

1.4 Overview .................... 5

2 Qualitativeness $\quad 7$

2.1 Qualitative vs. quantitative knowledge . . . . . . . . . 8

2.2 Properties of qualitative representations . . . . . . . . 8

2.3 Structured relational domains . . . . . . . . . . . . . 10

3 A cognitive perspective on knowledge representation 13

3.1 Issues in knowledge representation . . . . . . . . . . . . . 14

3.2 Knowledge representation model $\ldots \ldots \ldots \ldots \ldots$

3.3 Modalities of representation . . . . . . . . . . . . . . 19

3.3.1 The declarative/procedural distinction . . . . . . . 20

3.3.2 The propositional/analogical distinction . . . . . . . . 20

3.3.3 The qualitative/quantitative distinction . . . . . . . . 22

3.4 Summary . . . . . . . . . . . . . . . . . 23

4 Qualitative representation of positions in 2-D 25

4.12 -D scenes . . . . . . . . . . . . . . . . . . 26

4.1.1 Characteristics . . . . . . . . . . . . . 26

4.1 .2 Relevant dimensions . . . . . . . . . . . . . . 28

4.2 Arrangement . . . . . . . . . . . . . . . . . 29

4.3 Topological relations . . . . . . . . . . . . . . . . . 33

4.3.1 Systematic derivation of topological relations . . . . . . 34

4.3.2 Properties of the derived set . . . . . . . . . . . . . . 34

4.3.3 Structure of the topological domain . . . . . . . . 37

4.4 Orientation . . . . . . . . . . . . . . . . 39

4.4.1 Systematic derivation of orientation relations . . . . . . 40

4.4 .2 Structure of the orientation domain . . . . . . . . 43

4.4 .3 Reference frames . . . . . . . . . . . . . . . 44

4.4 .4 Objects with extension . . . . . . . . . . . . . 46 


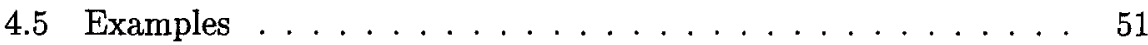

4.6 Summary . . . . . . . . . . . . . . . . 53

5 Reasoning with qualitative representations $\quad 55$

5.1 Transforming between frames of reference . . . . . . . . 56

5.2 Composition of spatial relations . . . . . . . . . . . 61

5.2.1 Composition of binary topological relations . . . . . . 61

5.2.2 Composition of orientation relations . . . . . . . 65

5.2.3 Composition of topological/orientation pairs $\ldots \ldots \ldots 6$

5.2 .4 Structure and table lookup . . . . . . . . . . . 68

5.2.5 The effect of multiple constraints . . . . . . . . . . 69

5.3 Constraint reasoning . . . . . . . . . . . . . . . . 69

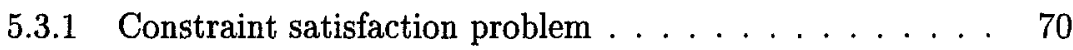

5.3.2 Consistency improvement . . . . . . . . . . . . 71

5.3 .3 Heuristics . . . . . . . . . . . . . . . . . . 74

5.4 Exploiting the structure of space $\ldots \ldots \ldots \ldots \ldots \ldots$

5.4.1 Combined structure of topological and orientation relations 75

5.4 .2 Abstract maps . . . . . . . . . . . . . 76

5.4 .3 Propagation heuristics . . . . . . . . . . . . . 80

5.4 .4 Constraint relaxation $\ldots \ldots \ldots \ldots 9$

5.4.5 Coarse reasoning and hierarchical organization . . . . 102

5.5 Summary . . . . . . . . . . . . . . . . . . 103

6 Applications 105

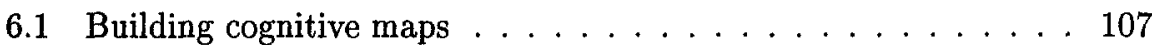

6.2 Visualization . . . . . . . . . . . . . . . 112

7 Extensions of the basic model $\quad 117$

$7.1 \quad 3$-D space . . . . . . . . . . . . . . . . . . 117

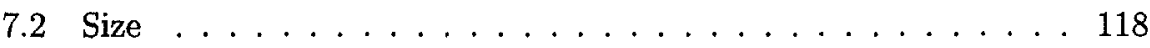

7.3 Distance . . . . . . . . . . . . . . . . . . 121

7.4 Shape . . . . . . . . . . . . . . . . . . 121

8 Relevant related work $\quad 129$

8.1 Other qualitative approaches to the representation of space . . . 129

8.1 .1 Interval algebras . . . . . . . . . . . . . 130

8.1 .2 Cartesian tuples of relations . . . . . . . . . . . . . 132

8.1.3 Other relational approaches . . . . . . . . . . . 134

8.2 Other approaches to the representation of spatial knowledge . . 140

8.2.1 Representation modalities . . . . . . . . . . . . . . 140

8.2.2 Cognitive maps and route finding . . . . . . . . . . . 143

8.2.3 Linguistically motivated research . . . . . . . . . . . 145

8.2 .4 Relational algebras . . . . . . . . . . . . . . . . 146 
9 Conclusion $\quad 149$

9.1 Main contributions . . . . . . . . . . . . . . . . . . 149

9.2 Future research issues . . . . . . . . . . . . . 150

9.3 Summary . . . . . . . . . . . . . . . . . . . 153

A Composition tables for various special cases $\quad 155$

$\begin{array}{ll}\text { Bibliography } & 165\end{array}$

$\begin{array}{ll}\text { Index } & 193\end{array}$ 